DE

M E D I C I N A

T R O P I C A L

DE

S ÃO PAULO

JOURNAL OF THE SÃO PAULO INSTITUTE OF TROPICAL MEDICINE

${ }^{1}$ Guangzhou Medical University, The Fifth Affiliated Hospital, Department of Infectious Diseases, Guangzhou, China

${ }^{2}$ Guangzhou Medical University, School of Public Health, Department of Preventive Medicine, Guangzhou, China

${ }^{3}$ Guangzhou Medical University, The Fifth Affiliated Hospital, Department of Obstetrics, Guangzhou, China

*These authors should be considered joint first authors

Correspondence to: Ouyang Shi Guangzhou Medical University, The Fifth Affiliated Hospital, Department of Infectious Disease, № 621 Harbour Road, Guangzhou, 510515, China

Fax: +86 2082291440

E-mail: ouyangshi@gzhmu.edu.cn

Received: 16 June 2020

Accepted: 11 August 2020

\section{Pregnancy and COVID-19: management and challenges}

\author{
Yao Wenling $^{1,2 *}$, Qiu Junchao ${ }^{3 *}$, Xiao Zhirong ${ }^{3 *}$, Ouyang Shi ${ }^{(1}$
}

\section{ABSTRACT}

The consequences of COVID-19 infecting pregnant women and the potential risks of vertical transmission have become a major issue. Since little is currently known about COVID-19 in pregnancy, the understanding of COVID-19 in this particular group will be updated in time, and a comprehensive review will be useful to evaluate the impact of COVID-19 in pregnancy. Based on recently published literature and official documents, this review provides an introduction to the pathogenesis, pathology, and clinical features of COVID-19 and has focused on the current researches on clinical features, pregnancy outcomes and placental histopathological analysis from pregnant women infected with SARS-CoV-2 in comparison with SARS-CoV and MERS-CoV. These viruses trigger a cytokine storm in the body, produce a series of immune responses, and cause changes in peripheral leukocytes and immune system cells leading to pregnancy complications that may be associated with viral infections. The expression of ACE2 receptors in the vascular endothelium may explain the histological changes of placentas from pregnant women infected by SARS-CoV-2. Pregnant women with COVID-19 pneumonia show similar clinical characteristics compared with non-pregnant counterparts. Although there is no unequivocal evidence to support the fetal infection by intrauterine vertical transmission of SARS, MERS and SARS-CoV-2 so far, more and more articles began to report maternal deaths due to COVID-19. In particular, from February 26, 2020 (date of the first COVID-19 case reported in Brazil) until June 18, 2020, Brazil reported 124 maternal deaths. Therefore, pregnant women and neonates require special attention regarding the prevention, diagnosis and management of COVID-19.

KEYWORDS: SARS-CoV-2. COVID-19. Pregnancy. Neonates. SARS. MERS. Vertical transmission.

\section{INTRODUCTION}

A series of a new coronavirus pneumonia ( $\mathrm{NCP}$ ), whose pathogen is the novel 2019 coronavirus $(2019-\mathrm{nCoV})$ was officially recognized by the World Health Organization on February 11, 2020 and the disease was called COVID-19. Meanwhile, the International Committee on Taxonomy of Viruses named the 2019 novel coronavirus as SARS-CoV-2. At 10:00 a.m. on March 30, 2020, a total of 82,447 confirmed cases and 3,310 deaths had been reported in China, with a case fatality rate of $4.0 \%$, while there were 693,224 confirmed cases and 33,106 deaths worldwide, with a case fatality rate of about $4.8 \%{ }^{1}$. Furthermore, the epidemic had a tendency to spread around the world. Therefore, the WHO has raised the global risk of the COVID-19 epidemic to the highest level (very high). Together with the other two highly pathogenic coronaviruses, the SARS-CoV and MERS-CoV, SARS-CoV-2 poses a global threat to public health. 
Pregnant women are particularly vulnerable to respiratory pathogens and severe pneumonia due to physiological and immunological changes, such as altered $\mathrm{T}$ lymphocyte immunity, increased oxygen consumption, decreased functional residual capacity and decreased chest compliance, which may result in higher maternal and fetal morbidity and mortality ${ }^{2}$. Furthermore, pregnant women with pneumonia have a significantly higher risk of giving birth to low birth weight, as well as preterm and, small for gestational age infants, with low Apgar scores, born by cesarean section, whose mothers presented with preeclampsia/ eclampsia more often than uninfected women ${ }^{3}$. However, there is still insufficient data to evaluate the impact of COVID-19 on pregnant women. Considering that SARS-CoV-2, SARS-CoV, and MERS-CoV are all $\beta$-coronaviruses, and their genomes, pathogenesis and clinical symptoms have certain similarities, this article draws lessons from previous studies on SARS-CoV and MERS-CoV infecting pregnant women to predict the impact of SARS-CoV-2 on pregnant women and fetuses and make some suggestions.

\section{Pathogenesis}

The functional receptor for SARS-CoV is the angiotensin-converting enzyme 2 (ACE2) ${ }^{4}$, which is abundantly present in lung alveolar epithelial cells and enterocytes of the small intestine, as well as in arterial and venous endothelial cells and arterial smooth muscle cells in virtually all of the organs ${ }^{5}$. In contrast, MERS-CoV uses the dipeptidyl peptidase 4 (DPP4) as its receptor ${ }^{6}$. DPP4 is widely expressed on epithelial cells in the kidney, alveoli, small intestine, liver, prostate and activated leukocytes ${ }^{7}$. SARS-CoV- 2 is a novel $\beta$-coronavirus from the subgenus Sarbecovirus, genetically similar to SARS-CoV (about $79 \%$ ) and MERS-CoV (about 50\%) ${ }^{8}$. Like in SARS-CoV infections, ACE2 is the cell receptor for SARS-CoV- $2^{9}$. The spike proteins of these viruses bind with cellular receptors of sensitive cells to mediate the infection of their target cells, after which viral replication begins in the cell cytoplasm.

SARS-CoV and MERS-CoV were both found to be able to show extremely high and early replication rates, infecting dendritic cells, macrophages and $\mathrm{T}$ cells $\mathrm{s}^{10-13}$, using several strategies to avoid the host innate immune response ${ }^{11,14}$, and resulting in a robust and sustained production of proinflammatory cytokines and chemokines ${ }^{11,12,15,16}$. Patients with COVID-19 have higher initial plasmatic concentrations of IL1 $\beta$ (Interleukin 1 Beta), IL1RA (Interleukin 1 Receptor Antagonist), IL7 (Interleukin 7), IL8 (Interleukin 8), IL9 (Interleukin 9), IL10 (Interleukin 10), basic FGF (basic
Fibroblast Growth Factor), GCSF (Granulocyte Colony Stimulating Factor), GMCSF (Granulocyte Macrophage Colony Stimulating Factor), IFN $\gamma$ (Interferon gamma), IP10 (Interferon Inducible Protein 10), MCP1 (Monocyte Chemotactic Protein 1), MIP1 $\alpha$ (Macrophage Inflammatory Protein-1 alpha), MIP1 $\beta$ (Macrophage Inflammatory Protein 1 Beta), PDGF (Platelet Derived Growth Factor), TNF $\alpha$ (Tumor Necrosis Factor alpha) and VEGF (Vascular Endothelial Growth Factor) than non-infected healthy adults $^{17}$. IL6 (Interleukin 6) levels in patients with severe COVID-19 were also significantly higher than in patients with milder infections ${ }^{18}$. These results suggest that the cytokine storm may also play a relevant role in the development of COVID-19.

\section{Pathology}

\section{Lung}

The pathological features of COVID-19 greatly resemble those seen in SARS and MERS coronavirus infections ${ }^{19-23}$. Diffuse alveolar damage is the predominant pulmonary histological pattern. Other changes included hyaline membrane formation, alveolar hemorrhage, desquamation of pneumocytes, extensive infiltration of neutrophils and macrophages in the interstice and alveoli.

An interesting report showed the pathological characteristics of a patient who died from a severe infection by SARS-CoV-2 and underwent postmortem biopsies $^{23}$. Both lungs showed diffuse alveolar damage with cellular fibromyxoid exudates and interstitial mononuclear inflammatory infiltrates, with predominance of lymphocytes. The right lung showed evident desquamation of pneumocytes and hyaline membrane formation and the left lung showed a pulmonary edema with hyaline membrane formation, related to the acute respiratory distress syndrome (ARDS). A recent study reported that the lung histopathology in the early phase of COVID-19 pneumonia include edema, proteinaceous exudate, focal reactive hyperplasia of pneumocytes with patchy inflammatory cellular infiltration, and multinucleated giant cells $^{24}$.

Diffuse alveolar damage with hyaline membranes and pulmonary edema play important roles in ARDS. Pregnant women with ARDS are more prone to hypoxia, their oxygen consumption is increased by $20 \%$ and their functional residual pulmonary capacity is decreased during pregnancy, rendering the woman intolerant to hypoxia. Severe pneumonia is characterized by hypoxemia, which subsequently leads to placental hypoxia. The hypoxic placenta releases antiangiogenic and proinflammatory factors that converge to the maternal endothelium, 
inducing endothelial dysfunction, hypertension, and organ damage ${ }^{25}$. Women with pneumonia during pregnancy have a significantly higher risk of adverse pregnancy outcomes, such as preterm delivery, pre-eclampsia, low birth weight and small-for-gestational-age infants ${ }^{2,3,26}$. Therefore, severe maternal respiratory distress syndrome may affect the fetal oxygen supply and endanger the fetus.

\section{Placenta}

In a study of the placental histopathology of mothers with SARS ${ }^{27}$, a total of seven placentas were studied. Two placentas from women recovering from SARS in the first trimester were normal. Three placentas from women that gave birth during the acute stage of SARS showed an increase in intervillous and subchorionic fibrin, and these findings may be related to disturbances in maternal placental blood flow due to hypoxia. Two placentas from women recovering from SARS in the third trimester of pregnancy were found to have an extensive thrombotic vasculopathy on the fetal side (FTV). The etiology of FTV may be related to the tendency to thrombosis due to SARS and/ or placental hypoxia. These two pregnancies were also accompanied by intrauterine growth restriction, oligohydramnios and small for gestation newborns.

A recent study analyzed the placental histopathology of three pregnant women who were infected by SARS-CoV-2 in the third trimester of pregnancy, and all of them presented with mild disease ${ }^{28}$. In one of the placentas a chorioangioma was evidenced, and another placenta showed multifocal infarctions. All three cases had varying degrees of increment of intervillous or subchorionic fibrin associated with increased syncytial nodules. No villitis or chorioamnionitis were found. Whether these changes were caused by placental ischemia due to 2019-nCoV infection still needs to be further investigated by enlarging the sample size.

In humans, maternal viral infections caused by AH1N1, dengue and HIV have been associated with impaired maternal and fetal hemodynamics and abnormal placental villous architecture. A healthy functioning placenta relies on a proper vascularization and perfusion of the placenta. Early studies indicated that systemic maternal infection and consequent inflammation can disrupt the placental vasculogenesis and angiogenesis and the alterations in placental hemodynamics may contribute to adverse pregnancy outcomes including preeclampsia, preterm delivery, small-for-gestational-age, low birth weight infants and stillbirths. In addition, it is believed that placental ischemia/ hypoxia can trigger an increased production of inflammatory biomarkers, such as IL6 and TNF $\alpha$, which contribute to endothelial dysfunction in preeclampsia $^{29}$.

\section{Clinical features}

The clinical features of SARS-CoV and MERS-CoV infections are similar but patients with MERS have a higher incidence of acute respiratory distress syndrome, which may explain why the fatality rate of SARS is about $10 \%$, while in MERS it is about $36 \%$. The major clinical features of SARS-CoV infections include persistent fever, chills or rigor, myalgia, dry cough, headache, malaise and dyspnea. Sore throat, rhinorrhea, sputum production, nausea, vomiting and dizziness were less common. In contrast, SARS and MERS-CoV infections usually start with fever, cough, chills, sore throat, myalgia and arthralgia, progressing with dyspnea and a rapid development of pneumonia within the first week, usually requiring respiratory support and ventilation, as well as other supportive measures ${ }^{30}$. In comparison with SARS, patients with MERS are older, with male predominance, a higher incidence of comorbidities and relatively lower human-to-human transmission potential ${ }^{31}$. Pregnant women infected with MERS may develop severe disease with fatal consequences, including stillbirths ${ }^{32-35}$.

The transmission route of COVID-19 is similar to the ones of SARS and MERS, mainly spread by respiratory droplets and direct contact. It is unclear if COVID-19 can be transmitted by the fecal-oral route, given that SARS-CoV-2 has been identified in stool specimens ${ }^{36}$. SARS-CoV-2 can also infect the lower respiratory tract and cause pneumonia, but its symptoms seem to be milder than in SARS and MERS ${ }^{37}$. Among all COVID-19 cases, severe manifestations accounted for $18.1 \%^{38}$. Data suggest an incubation period of about 5 days (range 2-14 days). Fever, cough, myalgia, fatigue and dyspnea were the most common clinical manifestations, whereas diarrhea, hemoptysis, headache, sore throat and shock only occur in a small number of patients ${ }^{17,38-41}$. Bilateral ground-glass or patchy opacities were the most common signs of radiological abnormalities ${ }^{17,38-41}$. Lymphopenia and eosinopenia were observed in most patients ${ }^{17,40-42}$. The viral load of 2019-nCoV detected from the patients' respiratory tract was positively correlated with the lung disease severity ${ }^{42}$. Complications of COVID-19 included the acute respiratory distress syndrome, anemia, acute cardiac injury, and exuberant secondary infections ${ }^{17}$. The majority of patients were older than 50 years ${ }^{39-41}$. SARSCoV-2 is more likely to affect elderly men suffering from chronic comorbidities that may lead to serious and even fatal respiratory failure ${ }^{41,43}$. The case fatality rate of patients with 2019-nCoV infection is lower than those of SARS and MERS. 


\section{SARS and pregnancy}

Twelve pregnant women were diagnosed with SARS in Hong Kong between February 1 and July 31, $2003^{44}$ All patients had high fever $\left(>38^{\circ} \mathrm{C}\right)$ and most presented with chills, rigor, malaise, myalgia and lymphopenia. Only $33 \%$ of the pregnant patients presented with shortness of breathe. Six $(50 \%)$ were admitted to intensive care units because of hypoxemia. Four (33\%) required mechanical ventilation, three of whom, died from respiratory failure or nosocomial infection. Among seven pregnant women in the first trimester, four had spontaneous miscarriages, two underwent termination of pregnancy due to social reasons and one had an uncomplicated ongoing pregnancy. All five newborns in the second and third trimester groups survived and four of them were delivered by cesarean section. Four newborns $(80 \%)$ were preterm and three of them were delivered by emergency cesarean sections due to the deterioration of maternal respiratory conditions. Among the live newborn infants, none had clinical or laboratory evidence of SARS-CoV2 infection.

Zhang et al. ${ }^{45}$ reported five primigravidas with SARS (including 2 twin pregnancies) from Guangzhou, China. Two were infected in the $2^{\text {nd }}$ trimester while the other three in the $3^{\text {rd }}$ trimester. Two presented with hospital-acquired infections and the other three had community-acquired infections. All five pregnant women had fever and abnormal chest X-ray. Other symptoms included cough $(n=4)$, hypoalbuminemia $(n=4)$, chills or rigor $(n=3)$, elevated alanine aminotransferase $(n=3)$, decreased lymphocytes $(n=2)$ and decreased platelet count $(n=2)$. All five pregnant women were cured with one of them required intensive care hospitalization. In a twin-pregnancy, one of the fetuses evolved to intrauterine death. The five neonates were followed-up and none had evidence of SARS.

There were no cases of vertical transmission identified among pregnant women infected with SARS ${ }^{44-49}$ so far, but SARS during pregnancy is associated with high incidences of spontaneous miscarriage, preterm delivery, intrauterine growth restriction, endotracheal intubation and admission to the neonatal intensive care unit ${ }^{44-46}$.

\section{MERS and pregnancy}

There are limited data on the clinical features of MERS$\mathrm{CoV}$ during pregnancy. Only 11 cases of MERS-CoV in pregnancy have been documented ${ }^{32-35,50,51}$. The clinical presentations of pregnant women with MERS were variable and ranged from asymptomatic presentations to shortness of breathe, fever, cough, myalgia and even fatal cases. Seven $(63.6 \%)$ patients required ICU hospitalization and three
(27\%) patients died during the hospital stay. Regarding the infants, three (27\%) infants died. Only one case resulted in both maternal and fetal death: the infant died four hours after birth and the mother died of severe refractory hypoxia and cardiac arrest 24 days after delivery. There were other two cases of intrauterine fetal demise, one maternal death for septic shock eight days after delivery, and one maternal death due to multiple organs failure 19 days after delivery. Few studies documented MERS-CoV testing in infants, except one report of an infant whose blood sample did not contain any $\operatorname{IgG}, \operatorname{IgM}$, or $\operatorname{Ig} \mathrm{A}$ antibodies raised to MERS-CoV ${ }^{52}$. Although data are limited, they also indicate that MERS infections may cause unfavorable clinical outcomes in pregnancy.

\section{COVID-19 and pregnancy}

Chen et al..$^{53}$ performed a retrospective review of medical records from nine pregnant women with COVID-19 pneumonia in the Zhongnan Hospital, Wuhan University, from January 20 to 31,2020. None of the nine patients developed severe pneumonia requiring mechanical ventilation or died of COVID-19 pneumonia (February 4, 2020). Seven of the nine patients presented with fever but none had high fever $\left(>39^{\circ} \mathrm{C}\right)$. Other symptoms, including cough $(\mathrm{n}=4)$, myalgia $(n=3)$, sore throat $(n=2)$, malaise $(n=2)$, lymphopenia $(n=5)$, and elevated CRP $(n=6)$ were also observed. All nine patients had cesarean sections during the third trimester and nine live births were recorded. One infant had a slightly increase in myocardial enzymes but without any clinical symptoms nine days after birth. None of the newborns needed special pediatric treatment. Neonatal throat swabs, amniotic fluid, cord blood and breast milk from six patients were tested, all of them were negative for SARS-COV-2.

Zhu et al..$^{54}$ retrospectively analyzed the clinical features and outcomes of 10 neonates, including two twins, whose mothers had COVID-19 and were hospitalized in five hospitals of Hubei, from January 20 to February 5, 2020. Among these nine pregnant women, the initial symptoms were fever and cough, one patient also had diarrhea. There were some prenatal complications including prematurity ( 5 to 7 hours before the onset of the true labor), intrauterine distress $(n=6)$, abnormal amniotic fluid $(n=2)$, rupture of membranes $(n=3)$, abnormal umbilical cord $(n=2)$, and abnormal placenta (placenta previa) $(n=1)$. Among these 10 newborns only four were full-term infants and the other six were preterm infants; and one was a large-forgestational-age (LGA) infant, while two were small-forgestational-age (SGA). The newborns' symptoms were mainly short of breathe $(n=6)$, digestive tract symptoms $(n=4)$, fever $(n=2)$, abnormal liver enzymes accompanied 
by thrombocytopenia $(n=2)$, neonatal respiratory distress syndrome (NRDS) $(n=2)$, increased heart rate $(n=1)$ and vomiting $(n=1)$. Until this article was published, five neonates had been cured and discharged from hospital, four neonates were still hospitalized in stable conditions and one died. Pharyngeal swab specimens were collected 1-9 days after birth, from nine of the 10 neonates, and none of them were positive to SRAS-CoV-2.

On February 5, 2020, one newborn whose mother had confirmed COVID-19, was admitted at the Wuhan Children's Hospital of Hubei Province presenting with stable vital signs, no fever or cough, normal liver function, absence of respiratory symptoms and normal chest X-ray. Throat swabs collected from the newborn 30 hours after birth were positive to SARS-CoV-2 but there was no direct evidence of intrauterine-acquired infection. Unfortunately, amniotic fluid, umbilical cord blood and placenta were not tested, thus one cannot conclude if this is a case of vertical transmission or a perinatal transmission by close contact with the infected mother. In the same hospital, another newborn had confirmed COVID-19 infection 17 days after birth and a history of close contact with two confirmed cases $^{55}$, the infant's mother and the maternity matron. In this case, there is no reliable evidence to support the vertical transmission of COVID-19.

One mother tested positive for SARS-CoV-2 two days after delivery ${ }^{56}$. She was admitted to the hospital due to elevation of her liver enzymes and had no fever or digestive tract symptoms when admitted to the hospital. COVID-19 was confirmed after delivery, and the prenatal infection cannot be ruled out. No SARS-CoV-2 was detected in the blood, urine, breast milk and in the throat swab of the newborn. There was no neonatal asphyxia, but the cardiac myoglobin and CK-MB enzymes were increased in the newborn, suggesting that a myocardial injury might exist.

Liu et al. ${ }^{57}$ reported 13 pregnant patients with laboratoryconfirmed SARS-CoV-2 infection admitted to hospitals outside of Wuhan between December 8, 2019, and February 25,2020 . Ten patients $(77 \%)$ presented with fever (range 37.3-39.0 ${ }^{\circ} \mathrm{C}$ ), mostly accompanied by fatigue. Three patients $(23 \%)$ complained of dyspnea and one patient (7.6\%) developed severe pneumonia with multiple organs dysfunction syndrome requiring ICU hospitalization in the third trimester. Three patients (23\%) improved after treatment and were discharged with an ongoing pregnancy. The other 10 patients $(77 \%)$ underwent caesarean sections. Five out of $10(50 \%)$ patients had pregnancy complications including fetal distress $(n=3)$, premature rupture of the membranes $(\mathrm{n}=1)$ and a stillbirth $(\mathrm{n}=1)$ and six patients $(60 \%)$ had preterm infants. No severe neonatal asphyxia was observed in the nine live births and no vertical transmission was found.
Yu et al. ${ }^{58}$ reported seven pregnant women with COVID-19 admitted to Tongji Hospital in Wuhan, China. Six patients (86\%) had fever, one patient (14\%) had cough, one patient (14\%) had shortness of breathe and one patient (14\%) had diarrhea. Chest tomography (CT) revealed that six patients $(86 \%)$ had bilateral pneumonia and one patient $(14 \%)$ had unilateral pneumonia. No one needed ICU hospitalization and the outcomes of these pregnant women were favorable. Among three infants tested for SARS-CoV-2, one was positive to SARS-CoV-2 in a throat swab $36 \mathrm{~h}$ after birth. This infant had a mild pulmonary infection and mild shortness of breathe, no fever or cough. In addition, the placenta and cord blood of this infant were negative for SARS-CoV-2 by RT-PCR so that intrauterine vertical transmission may not have occurred.

Since Ahmed et al..$^{59}$ reported the first maternal death of a 29-year-old Pakistani woman was reported in the Heart Zone Hospital in Birmingham, UK on April 8, 2020, more and more articles began to report maternal deaths due to COVID-19. In particular, from February 26, 2020 (date of the first COVID-19 reported case in Brazil) until June 18, 2020, Brazil had already reported 124 maternal deaths, in the same period Mexico had reported seven maternal deaths ${ }^{60}$. Brazil's elevated COVID-19 mortality rate in pregnancy might have several explanations. Firstly, a possible shortage of healthcare providers and lack of intensive care resources are some of the chronic challenges in Brazilian health care. Secondly, Brazil has a higher cesarean section rate than most countries firstly hit by COVID- $19^{60}$. A comparison of pregnant women from the above described studies is shown in Table 1.

\section{CONCLUSION}

This is a review on pregnant women infected by SARS-CoV-2, SARS, and MERS, including their pathogenesis, clinical manifestations and pregnancy outcomes. These viruses mainly spread through the respiratory mucosa and infect other target cells, triggering a cytokine storm in the body, producing a series of immune responses and causing changes in peripheral leukocytes and immune system cells such as lymphocytes, which might be an important pathological pathway that inhibits the body's cellular immune function, leading to the deterioration of the patient's condition. The angiotensin-converting enzyme 2 (ACE2) has been identified as the functional receptor for SARS-CoV-2 and SARS-CoV. The fact that ACE2 is abundantly present in the epithelia of the lungs and small intestine, provides a possible explanation for the pathological lung and gastrointestinal symptoms. The abundant expression of ACE2 in alveolar cells may 
Table 1 - A comparison of pregnant women with SARS, MERS and SARS-CoV-2 infections.

\begin{tabular}{lccc}
\hline & SARS & MERS & SARS-CoV-2 \\
& {$[63,64]$} & {$[72,73,76,77]$} & 38 \\
\hline Number of patients & 17 & $11-54,69-70]$ & $24-40$ \\
Age range(year) & $23-44$ & $27-39$ & $31(81.6 \%)$ \\
Fever, $n(\%)$ & $17(100 \%)$ & $5(45.5 \%)$ & $11(28.9 \%)$ \\
Cough, $n(\%)$ & $13(76.5 \%)$ & $7(63.6 \%)$ & $1(2.6 \%)$ \\
ICU admission, $\mathrm{n}(\%)$ & $7(41.2 \%)$ & $7(63.6 \%)$ & $38(100 \%)$ \\
Maternal survival, $\mathrm{n}(\%)$ & $14(82.4 \%)$ & $8(72.7 \%)$ & $37(94.9 \%)$ \\
Fetal survival, $\mathrm{n}(\%)$ & $11(64.7 \%)$ & $8(72.7 \%)$ & $36(94.7 \%)$ \\
C-section, $\mathrm{n}(\%)$ & $8(47.0 \%)$ & $4(36.4 \%)$ & \\
\hline
\end{tabular}

cause a rapid viral expansion and destruction of the alveolar wall, resulting in a rapid progression of extensive pulmonary consolidations and diffuse alveolar damage with hyaline membrane formation. Its presence in the vascular endothelium might also provide a step forward in understanding the histological changes of placentas from pregnant women infected by SARS-CoV-2. The clinical manifestations of COVID-19 infection also show great similarities with SARS and MERS. However, COVID-19 has affected more people in a shorter period of time compared to SARS and MERS, although with a lower fatality rate than SARS and MERS. Pregnant women with COVID-19 pneumonia showed a similar pattern in comparison with non-pregnant counterparts, including fever, cough, myalgia, fatigue, shortness of breathe or asymptomatic presentation. It is worth noting that there is currently no evidence that pregnant women with COVID-19 are at higher risk of severe illness. However, SARS and MERS were found to be greatly associated with severe maternal illness, spontaneous abortion and even maternal death and intrauterine fetal demise. Some pregnancy complications have occurred in pregnant women with COVID-19, such as fetal distress, premature rupture of membranes, preterm deliveries and stillbirths. Furthermore, these pregnancy complications might be closely related to the cytokine storm, lung injury and placental ischemia/ hypoxia caused by SARS-CoV-2 infections. Although there is currently no evidence to support the fetal infection by intrauterine vertical transmission of SARS, MERS, and COVID-19, more and more articles began to report maternal deaths due to COVID-19. In particular, from February 26, 2020 (date of the first COVID-19 case in Brazil) until June 18, 2020, Brazil had already reported 124 maternal deaths. Thus, we should be alert that these diseases may follow the same trend of greater severity and poorer prognosis in pregnant women. Therefore, pregnant women and newborns require special attention in the prevention, diagnosis and management of COVID-19.
The maternal physiological and immune function changes in pregnancy make pregnant women more susceptible to COVID-19. Furthermore, considering that pregnant women with COVID-19 may not have typical symptoms such as fever, we suggest that pregnant women with any symptoms suggestive of COVID-19 should undergo careful examination to prevent adverse pregnancy outcomes. COVID-19 infection itself is not an indication for cesarean section deliveries. The timing and mode of delivery should be individualized based on the disease severity, pre-existing maternal comorbidities, obstetric history, gestational age and fetal conditions. Newborns from women with suspected or confirmed COVID-19 should undergo a careful examination, and have the body temperature, respiratory rate and heart rate closely monitored, as well as digestive tract symptoms. So far, breast milk samples were negative for SARS-CoV-2 and this virus is mainly transmitted by respiratory droplets and close contact. Furthermore, the protective effect of breastfeeding on newborns is particularly strong. Precautions should be taken to enable infected mothers to breastfeed, including respiratory hygiene, hand hygiene and disinfection, the use of N-95 masks by the mother while breastfeeding in cases in which mothers or newborns are suspected of or have confirmed COVID-19.

Personal protection must be taken in order to minimize the risk of contracting the virus. Future researches should cover different pregnant stages of COVID-19 as much as possible. It is recommended that the placenta and other tissues of pregnant women with 2019-nCov infection should be evaluated by histopathological examinations, to provide more detailed pathological analyses. The epidemic situation of COVID-19 is still spreading, and this review has limitations. Thus, further investigation is needed to elucidate how COVID-19 affects pregnant women and fetuses, as well as the exact impact of COVID-19 on pregnant women themself and on pregnancy outcomes. 


\section{AUTHORS' CONTRIBUTIONS}

Yao W, Qiu J and Xiao Z had the idea for the article and performed the literature search and data analysis. The first draft of the manuscript was written by Yao W and all authors critically revised the previous versions of the manuscript. All authors read and approved the final manuscript.

\section{CONFLICT OF INTERESTS}

We declare no conflict of interests.

\section{FUNDING}

This work was supported by the National Natural Science Foundation of China, grant $\mathrm{N}^{\mathrm{o}} 81803884$

\section{REFERENCES}

1. World Health Organization. Coronavirus disease 2019 (COVID-19): situation report - 70. [cited 2020 Aug 11]. Available from: https://www.who.int/docs/default-source/ coronaviruse/situation-reports/20200330-sitrep-70-covid-19. pdf?sfvrsn=7e0fe3f8_2

2. Tang P, Wang J, Song Y. Characteristics and pregnancy outcomes of patients with severe pneumonia complicating pregnancy: a retrospective study of 12 cases and a literature review. BMC Pregnancy Childbirth. 2018;18:434.

3. Chen YH, Keller J, Wang IT, Lin CC, Lin HC. Pneumonia and pregnancy outcomes: a nationwide population-based study. Am J Obstet Gynecol. 2012;207:288.e1-7.

4. Li W, Moore MJ, Vasilieva N, Sui J, Wong SK, Berne MA, et al. Angiotensin-converting enzyme 2 is a functional receptor for the SARS coronavirus. Nature. 2003;426:450-4.

5. Hamming I, Timens W, Bulthuis ML, Lely AT., Navis G, van Goor H. Tissue distribution of ACE2 protein, the functional receptor for SARS coronavirus: a first step in understanding SARS pathogenesis. J Pathol. 2004;203:631-7.

6. Raj VS, Mou H, Smits SL, Dekkers DH, Müller MA, Dijkman $\mathrm{R}$, et al. Dipeptidyl peptidase 4 is a functional receptor for the emerging human coronavirus-EMC. Nature. 2013;495:251-4.

7. Widagdo W, Raj VS, Schipper D, Kolijn K, van Leenders GJ, Bosch BJ, et al. Differential expression of the Middle East respiratory syndrome coronavirus receptor in the upper respiratory tracts of humans and dromedary camels. J Virol. 2016;90:4838-42.

8. Lu R, Zhao X, Li J, Niu P, Yang B, Wu H, et al. Genomic characterisation and epidemiology of 2019 novel coronavirus: implications for virus origins and receptor binding. Lancet. 2020;395:565-74.
9. Zhou P, Yang XL, Wang XG, Hu B, Zhang L, Zhang W, et al. A pneumonia outbreak associated with a new coronavirus of probable bat origin. Nature. 2020;579:270-3.

10. Spiegel M, Schneider K, Weber F, Weidmann M, Hufert FT. Interaction of severe acute respiratory syndrome-associated coronavirus with dendritic cells. J Gen Virol. 2006;87:1953-60.

11. Chu H, Zhou J, Wong BH, Li C, Cheng ZS, Lin X, et al. Productive replication of Middle East respiratory syndrome coronavirus in monocyte-derived dendritic cells modulates innate immune response. Virology. 2014;454-455:197-205.

12. Zhou J, Chu H, Li C, Wong BH, Cheng ZS, Poon VK, et al. Active replication of Middle East respiratory syndrome coronavirus and aberrant induction of inflammatory cytokines and chemokines in human macrophages: implications for pathogenesis. J Infect Dis. 2014;209:1331-42.

13. Chu H, Zhou J, Wong BH, Li C, Chan JF, Cheng ZS, et al. Middle East respiratory syndrome coronavirus efficiently infects human primary $\mathrm{T}$ lymphocytes and activates the extrinsic and intrinsic apoptosis pathways. J Infect Dis. 2016;213:904-14.

14. de Wit E, van Doremalen N, Falzarano D, Munster VJ. SARS and MERS: recent insights into emerging coronaviruses. Nat Rev Microbiol. 2016;14:523-34.

15. Wong CK, Lam CW, Wu AK, Ip WK, Lee NL, Chan IH, et al. Plasma inflammatory cytokines and chemokines in severe acute respiratory syndrome. Clin Exp Immunol. 2004;136:95103.

16. Kong SL, Chui P, Lim B, Salto-Tellez M. Elucidating the molecular physiopathology of acute respiratory distress syndrome in severe acute respiratory syndrome patients. Virus Res. 2009;145:260-9.

17. Huang C, Wang Y, Li X, Ren L, Zhao J, Hu Y, et al. Clinical features of patients infected with 2019 novel coronavirus in Wuhan, China. Lancet. 2020;395:497-506.

18. Wan S, Yi Q, Fan S, Lv J, Zhang X, Guo L, et al. Characteristics of lymphocyte subsets and cytokines in peripheral blood of 123 hospitalized patients with 2019 novel coronavirus pneumonia(NCP)[J/OL]. medRxiv, 2020 In Press.

19. Ding Y, Wang H, Shen H, Li Z, Geng J, Han H, et al. The clinical pathology of severe acute respiratory syndrome (SARS): a report from China J Pathol. 2003;200:282-9.

20. Gu J, Gong E, Zhang B, Zheng J, Gao Z, Zhong Y, et al. Multiple organ infection and the pathogenesis of SARS. J Exp Med. 2005;202:415-24.

21. Nicholls JM, Poon LL, Lee KC, Ng WF, Lai ST, Leung CY, et al. Lung pathology of fatal severe acute respiratory syndrome. Lancet. 2003;361(9371):1773-1778.

22. Ng DL, Al Hosani F, Keating MK, Gerber SI, Jones TL, Metcalfe MG, et al. Clinicopathologic, immunohistochemical, and ultrastructural findings of a fatal case of Middle East respiratory syndrome coronavirus infection in the United Arab Emirates, April 2014.Am J Pathol. 2016;186:652-8 
23. Xu Z, Shi L, Wang Y, Zhang J, Huang L, Zhang C, et al. Pathological findings of COVID-19 associated with acute respiratory distress syndrome. Lancet Respir Med. 2020;8:4202.

24. Tian S, Hu W, Niu L, Liu H, Xu H, Xiao SY. Pulmonary pathology of early-phase 2019 novel coronavirus (COVID-19) pneumonia in two patients with lung cancer. J Thorac Oncol. 2020;15:7004.

25. Sava RI, March KL, Pepine CJ. Hypertension in pregnancy: taking cues from pathophysiology for clinical practice. Clin Cardiol. 2018;41:220-7.

26. Romanyuk V, Raichel L, Sergienko R, Sheiner E. Pneumonia during pregnancy: radiological characteristics, predisposing factors and pregnancy outcomes. J Matern Fetal Neonatal Med. 2011;24:113-7.

27. Ng WF, Wong SF, Lam A, Mak YF, Yao H, Lee KC, et al. The placentas of patients with severe acute respiratory syndrome: a pathophysiological evaluation. Pathology. 2006;38:210-8.

28. Chen S, Huang B, Luo DJ, Li X, Yang F, Zhao Y, et al. Pregnant women with new coronavirus infection: a clinical characteristics and placental pathological analysis of three cases. Zhonghua Bing Li Xue Za Zhi. 2020;49:418-23.

29. Gilbert JS, Ryan MJ, LaMarca BB, Sedeek M, Murphy SR, Granger JP. Pathophysiology of hypertension during preeclampsia: linking placental ischemia with endothelial dysfunction. Am J Physiol Heart Circ Physiol. 2008;294:H541-50.

30. Assiri A, Al-Tawfiq JA, Al-Rabeeah AA, Al-Rabiah FA, Al-Hajjar $\mathrm{S}$, Al-Barrak A, et al. Epidemiological, demographic, and clinical characteristics of 47 cases of Middle East respiratory syndrome coronavirus disease from Saudi Arabia: a descriptive study. Lancet Infect Dis. 2013;13:752-61.

31. Hui DS, Memish ZA, Zumla A. Severe acute respiratory syndrome vs. the Middle East respiratory syndrome. Curr Opin Pulm Med. 2014;20:233-41.

32. Assiri A, Abedi GR, Al Masri M, Bin Saeed A, Gerber SI, Watson JT. Middle East respiratory syndrome coronavirus infection during pregnancy: a report of 5 cases from Saudi Arabia. Clin Infect Dis. 2016;63:951-3.

33. Alserehi H, Wali G, Alshukairi A, Alraddadi B. Impact of Middle East Respiratory Syndrome coronavirus (MERS$\mathrm{CoV}$ ) on pregnancy and perinatal outcome. BMC Infect Dis. 2016;16:105.

34. Malik A, El Masry KM, Ravi M, Sayed F. Middle East Respiratory Syndrome Coronavirus during Pregnancy, Abu Dhabi, United Arab Emirates, 2013. Emerg Infect Dis. 2016;22:515-7.

35. Payne DC, Iblan I, Alqasrawi S, Al Nsour M, Rha B, Tohme RA, et al. Stillbirth during infection with Middle East respiratory syndrome coronavirus. J Infect Dis. 2014;209:1870-2.

36. Holshue ML, DeBolt C, Lindquist S, Lofy KH, Wiesman J, Bruce H, et al. First Case of 2019 novel coronavirus in the United States. N Engl J Med. 2020;382:929-36.
37. Chen Y, Liu Q, Guo D. Emerging coronaviruses: Genome structure, replication, and pathogenesis. J Med Virol. 2020;92:418-23.

38. Sun P, Qie S, Liu Z, Ren J, Li K, Xi J. Clinical characteristics of hospitalized patients with SARS-CoV-2 infection: a single arm meta-analysis. J Med Virol. 2020;92:612-7.

39. Chen N, Zhou M, Dong X, Qu J, Gong F, Han Y, et al. Epidemiological and clinical characteristics of 99 cases of 2019 novel coronavirus pneumonia in Wuhan, China: a descriptive study. Lancet. 2020;395:507-13.

40. Zhang JJ, Dong X, Cao YY, Yuan YD, Yang YB, Yan YQ, et al. Clinical characteristics of 140 patients infected with SARS-CoV-2 in Wuhan, China. Allergy. 2020 In Press.

41. Wang D, Hu B, Hu C, Zhu F, Liu X, Zhang J, et al. Clinical characteristics of 138 hospitalized patients with 2019 novel coronavirus-infected pneumonia in Wuhan, China. JAMA. 2020;323:1061-9.

42. Liu Y, Yang Y, Zhang C, Huang F, Wang F, Yuan J, et al. Clinical and biochemical indexes from 2019-nCoV infected patients linked to viral loads and lung injury. Sci China Life Sci. 2020;63:364-74.

43. Li Q, Guan X, Wu P, Wang X, Zhou L, Tong Y, et al. Early transmission dynamics in Wuhan, China, of novel coronavirusinfected pneumonia. N Engl J Med. 2020;382:1199-207.

44. Wong SF, Chow KM, Leung TN, Ng WF, Ng TK, Shek CC, et al. Pregnancy and perinatal outcomes of women with severe acute respiratory syndrome. Am J Obstet Gynecol. 2004;191:292-7.

45. Zhang JP, Wang YH, Chen LN, Zhang R, Xie YF. Clinical analysis of pregnancy in second and third trimesters complicated severe acute respiratory syndrome. Zhonghua Fu Chan Ke Za Zhi. 2003;38:516-20.

46. Stockman LJ, Lowther SA, Coy K, Saw J, Parashar UD. SARS during pregnancy, United States. Emerg Infect Dis. 2004; 10:1689-90.

47. Maxwell C, McGeer A, Tai KF, Sermer M. No. 225-Management Guidelines for Obstetric Patients and Neonates Born to Mothers With Suspected or Probable Severe Acute Respiratory Syndrome (SARS). J Obstet Gynaecol Can. 2017;39:e130-7.

48. Robertson CA, Lowther SA, Birch T, Tan C, Sorhage F, Stockman L, et al. SARS and pregnancy: a case report. Emerg Infect Dis. 2004; 10:345-8.

49. Schneider E, Duncan D, Reiken M, Perry R, Messick J, Sheedy C, et al. SARS in pregnancy. AWHONN Lifelines. 2004;8:122-8.

50. Alfaraj SH, Al-Tawfiq JA, Memish ZA. Middle East respiratory syndrome coronavirus (MERS-CoV) infection during pregnancy: report of two cases \& review of the literature. J Microbiol Immunol Infect. 2019;52:501-3.

51. Park MH, Kim HR, Choi DH, Sung JH, Kim JH. Emergency cesarean section in an epidemic of the Middle East respiratory syndrome: a case report. Korean J Anesthesiol. 2016;69:28791. 
52. Jeong SY, Sung SI, Sung JH, Ahn SY, Kang ES, Chang YS, et al. MERS-CoV infection in a pregnant woman in Korea. J Korean Med Sci. 2017;32:1717-20.

53. Chen H, Guo J, Wang C, Luo F, Yu X, Zhang W, et al. Clinical characteristics and intrauterine vertical transmission potential of COVID-19 infection in nine pregnant women: a retrospective review of medical records. Lancet. 2020;395:809-15.

54. Zhu H, Wang L, Fang C, Peng S, Zhang L, Chang G, et al. Clinical analysis of 10 neonates born to mothers with 2019-nCoV pneumonia. Transl Pediatr. 2020;9:51-60.

55. Zhang Z, Wang C, Gao CC. Neonatal coronavirus expert confirmed at 30 hours of birth: vertical transmission from mother to infant. [cited 2020 Aug 11]. Available from: http://www.cnr.cn/hubei/ yuanchuang/20200205/t20200205_524961963.shtml

56. Zhuang S, Guo J, Cao Y, Chen H, Xu D, Li J, et al. Perinatal COVID-19: a case report. Chin J Perinat Med. 2020;23:85-90.
57. Liu Y, Chen H, Tang K, Guo Y. Clinical manifestations and outcome of SARS-CoV-2 infection during pregnancy. J Infect. 2020 In Press.

58. Yu N, Li W, Kang Q, Xiong Z, Wang S, Liu X, et al. Clinical features and obstetric and neonatal outcomes of pregnant patients with COVID-19 in Wuhan, China: a retrospective, single-centre, descriptive study. Lancet Infect Dis. 2020;20:559-64.

59. Ahmed I, Azhar A, Eltaweel N, Tan BK. First COVID-19 maternal mortality in the UK associated with thrombotic complications. Br J Haematol. 2020;190:e37-8.

60. Takemoto ML, Menezes MO, Andreucci CB, Nakamura-Pereira M, Amorim MM, Katz L, et al. The tragedy of COVID-19 in Brazil: 124 maternal deaths and counting. Int J Gynaecol Obstet. 2020 In Press. 